\title{
CONSEQUENCES OF SPECIES GROUPING FOR FOOD WEB STRUCTURE
}

\author{
SÁNCHEZ-CARMONA, R.* - RODRÍGUEZ-RUIZ, A. - ENCINA ENCINA, L. - \\ RODRÍGUEZ-SÁNCHEZ, M.V. - GRANADO-LORENCIO, C.
}

Department of Plant Biology and Ecology, Faculty of Biology, University of Seville, P.O. Box. 1095. 41080 Seville, Spain

(phone: +34954557065 ; fax: +34954626308 )

*Corresponding author: ramoni@us.es

(Received $2^{\text {nd }}$ December 2011; accepted $10^{\text {th }}$ February 2012)

\begin{abstract}
Effects of trophic species aggregation on the structural properties of food webs in six Mediterranean streams were assessed here. In each stream, we created three different variations of the original food web, according to the trophic species aggregation applied. The aggregations used here were based on predator-prey relationships, i.e., species were lumped at different levels of trophic habits in the food web into top (T), intermediate (I) and basal (B) species. In our studied food webs, these species corresponded to fishes, macroinvertebrates and different types of detritus, respectively. No significant differences were found in structural properties when we analyzed the stream effect, but these were found in the analysis of aggregation variation effect. Species grouping, and the level within the food web at which it occurs, influenced the structural properties of the food web. However, these properties were comparable between all the studied streams when the same resolution was considered. The relationship between omnivory and connectance was not affected by trophic species grouping. These properties were positively and significantly related in all aggregation variations of the food webs, suggesting that the stabilizing role of omnivory is maintained regardless of the particular grouping method utilized.
\end{abstract}

Keywords: structural properties, Mediterranean streams, omnivory, connectance

\section{Introduction}

Published food web studies vary in terms of methodology, criteria for defining links and in the level and standardization of taxonomic resolution. Some of these factors have now been shown to affect estimates of food web properties (Closs, 1991; Cohen et al., 1993; Tavares-Cromar and Williams, 1996; Thompson and Townsend, 2000; Hildrew, 2009).

Identification of the elements that comprise an ecosystem, and the connections between these elements, involves critical assumptions that have proven influential for the results of further analysis (Goldwasser and Roughgarden, 1997; Martinez et al., 1999; Abarca-Arenas and Ulanowicz, 2002; Allesina et al., 2005). In many studies, even when a certain resolution is desirable, adhering to a criterion of resolution to the level of species may not be possible because detailed information is inaccessible and/or the hypothetical sampling effort is unfeasible (Gaedke, 1995; Martinez et al., 1999). Thus, the aggregation of food web components by researchers is a complex task in which decisions taken regarding grouping method may introduce bias to the created food web.

Researchers have been criticised for their failure to resolve webs to the highest possible level of taxonomic resolution (Cohen et al., 1993). For this reason, the effect of taxonomic resolution is a critical issue in various works (Martinez, 1991; Thompson and Townsend, 2000). The effects of lumping upon food web analysis have been 
explored, (e.g. Yodzis, 1984; Lawton and Warren, 1988; Martinez, 1993; Martinez, 1994; Martinez and Lawton, 1995; Polis and Hurd, 1995; Winemiller, 1996; Pimm, 2002) but this issue requires further examination. In order to study, control and possibly reduce the effects of this variability in ecological network, some authors have evaluated the effects of aggregation on study results and conclusions (Hall and Raffaeli, 1991; Martinez, 1991; Goldwasser and Roughgarden, 1997: Sugihara et al., 1997; AbarcaArena and Ulanowicz, 2002; Allesina et al., 2005).

Aggregation can range from the simplest of schemes involving primary producers, consumers and decomposers/detritus (Fath et al., 2007), to the most disaggregated scheme based on available data, where the concept of a food web compartment may refer to a species or even to an age- or size-class of a species (Johnson et al., 2005). In a review of available food web data, we observed that the level within the food web at which species lumping normally occurs is dependent upon the type of ecosystem in question. For example, the most common task in marine ecosystems is the aggregation of primary producers into phytoplankton, microphytobenthos and macrophytes, according to size and habitat. Since identifying organisms to species is a laborious task, species in the consumer groups such as bacteria, zooplankton and meiofauna usually remain undifferentiated, while information about higher trophic levels is more available and aggregation of data is not required to the same extent. In smaller ecosystems such as lagoons or streams however, lower or intermediate trophic levels (invertebrates, zooplankton or phytoplankton) are defined with more resolution while higher trophic levels appear grouped in single taxa (e.g. fish, birds) (Motta and Uieda, 2005; Liu et al., 2006).

This study focused on the common exercise of grouping species in order to highlight the part of the food web of most interest to researchers. This practice is carried out, according to the criteria and convenience of each researcher, because it is impossible to include the whole food web even if its boundaries are relatively limited. In this study, the food webs of six previously analysed Mediterranean streams were used to assess the effects of species lumping at different trophic habit levels through the construction of aggregated variations of food webs, thereby focusing attention upon a specific level of the trophic web. Thus, the purpose here is not to analyse these food webs exhaustively or to comment on the patterns they display. The existence of these six comparable food webs allowed us to investigate the consequences of grouping the components of one part of the food web upon the structure of that web.

\section{Methods}

\section{Study areas}

The Mediterranean streams analyzed as part of this study are located within three hydrologic demarcations located in the Southern Iberian Peninsula: South basin, Guadalquivir basin and Guadiana basin.

The South basin extends along the eastern edge of Andalusia, covering a strip some $50 \mathrm{~km}$ wide and $350 \mathrm{~km}$ long, extending over an area of $18425 \mathrm{~km}^{2}$. This basin includes the Hozgarganta (HZ) and Guadiaro (GDR) streams. The former (HZ) is located in the Alcornocales Natural Park (Cádiz, Andalusia) and is one of the few unregulated streams throughout the basin in the Iberian Peninsula, and the only one in Andalusia (Garrido and Hidalgo, 2000). Its basin has a length of $56.4 \mathrm{~km}$ and an area of $357.68 \mathrm{~km}^{2}$ and is characterized by notable ecological richness and an excellent state of conservation. The 
Guadiaro stream is $101 \mathrm{~km}$ in length and covers an area of $1489 \mathrm{~km}^{2}$. The banks of these streams feature communities with an abundance of deciduous plant species, including poplar (Populus alba), alder (Alnus glutinosa) and willow (Salix alba).

The Guadalquivir basin has an area of $57527 \mathrm{~km}^{2}$. This basin includes the Rivera de Cala (CL) and Guadiamar (GDM) streams. The former (CL) marks the boundary between two protected natural areas: the Aracena Mountain Range and Aroche Peaks Natural Park and the North Mountain Range Natural Park. The Guadiamar has its source in the western foothills of the Sierra Morena and flows more than $80 \mathrm{~km}$ to enter the Guadalquivir river, running through the marshes of the Guadalquivir in the Doñana National Park. The Sierra Morena area is physically very homogeneous and features a mountainous environment with gentle slopes. It provides a habitat for bushes of rockrose (Cistus ladanifer), holm oak (Quercus rotundifolia) and cork oak (Quercus suber).

The Guadiana basin is located in the south-western quadrant of the Iberian Peninsula, forming the border between Spain and Portugal along its last stretch. This is a territory typified by both wet and arid areas, with $67147 \mathrm{~km}^{2}$ of river network. This basin includes the Odiel (OD) and the Rivera de Chanza $(\mathrm{CH})$ streams. The Odiel rises in the Aracena Mountain Range at an altitude of $660 \mathrm{~m}$. The Rivera de Chanza rises in the western foothills of the Sierra Morena and, in its final stretch, forms the border with Portugal until its confluence with the Guadiana River. In terms of vegetation, the higher area is characterized by pasture with Holm oak (Quercus ilex) and scrub with areas of pine repopulation.

These streams are subject to a characteristic climatic regime of seasonal droughts (summer to the beginning of autumn) and inflows (from the end of autumn through the winter), which are predictable but highly variable between years (Gasith and Resh, 1999). They are characterized by a low diversity and species richness of fish. The native freshwater fish fauna of the Iberian Peninsula is characterized by a low number of families, with most species belonging to the family Cyprinidae, a high degree of diversification at species level, and the highest percentage of endemism in Europe (Doadrio, 2001). However, the macroinvertebrate fauna has higher values of diversity and species richness.

\section{Food web construction}

Binary food webs were constructed for each of the six streams. Sampling of macroinvertebrate communities and fish assemblages was conducted during the spring of 2004 to avoid both winter flooding and the arid conditions of summer, which cause high habitat loss, decrease in habitat connectivity and a large decline in the fish populations.

Samples of benthic macroinvertebrates were taken from twenty-four Suber Samplers (area $0.05 \mathrm{~m}^{2}$, mesh size $250 \mu \mathrm{m}$ ), located at regular intervals along each selected reach, and preserved in $70 \%$ ethanol. Macroinvertebrates were sorted and identified to the highest taxonomic resolution possible using Tachet et al. (2003). 63\% taxa were identified to genus or species and $37 \%$ to family or subfamily. Fish were sampled using electrofishing, operated at $300 \mathrm{~W}$ with a voltage of $220 \mathrm{~V}$ and a direct current of 0.6-0.7 A. General identification of fish was conducted following Kottelat and Freyhof (2007). Depending on the catch, a maximum of fifteen individuals were selected from each species and age per stream to represent the full size range; these were used for gut analysis while the remainder were returned to the water. Gut analysis was carried out 
under a binocular magnifying glass, and involved identification of each different component of the gut contents. The fresh weight of each item identified in the gut was expressed as a percentage of the total diet, assuming the fresh weight of the total stomach contents to represent 100\% (Pinkas et al., 1971).

In the construction of the binary food webs for each stream, data from gut contents were used to describe the trophic structure of the fish assemblages. Macroinvertebrate trophic structure was described using data sourced from relevant literature (Cummins and Klug, 1979; Tachet et al., 2003). Each macroinvertebrate was assigned a Functional Feeding Group (FFG). This technique groups species together based on similarity of feeding characteristics. The groups used in this analysis were based on those of Merrit and Cummins (1996). Species were classified as scrapers (feed on algae), shredders (feed on coarse organic material, e.g., leaves, wood), collectors (feed on fine detritus deposited on the substrate), filterers (feed on fine detritus suspended in the water column) and finally, predators (feed on other macroinvertebrates).

Lower trophic taxa were aggregated into the following larger taxa groups: periphyton algae, macrophytes, allochthonous vegetal debris, allochthonous animal debris, coarse particulate organic matter (CPOM), suspended and deposited fine particulate organic matter (FPOM), and benthic detritus.

The term taxa was used to refer to groups of organisms identified by the investigators as the core units of analysis in the food webs. These range from species (e.g. barbels), to species grouped by trophic habit, taxonomy, or other criteria (e.g. benthic filter feeders, zooplankton), to mixed pools (e.g. detritus - a combination of live organism, organic matter, and inorganic matter) (Dunne et al., 2004). Trophic species are groups of taxa whose members share the same set of predators and prey (sensu Paine, 1980). This study focused on the food webs of trophic species.

\section{Construction of aggregations variations of food webs}

The expanded original food web (of maximum resolution in fish and macroinvertebrates and considering different forms of detritus) was considered to represent the control, from which a series of aggregation variations of the food web were produced.

In common with the goals of Abarca-Arenas and Ulanowicz (2002) in their study regarding the effects of taxonomic aggregation on network analysis, our objective in this study was to assume the role of a researcher who would normally lump species, or groups of species, in an intuitive way. For this reason, no one numerical classification method of species aggregation was used. The aggregations used in this study were based on predator-prey relationships, i.e. species were lumped at different levels of trophic habits in the food web: Top species (T: species with prey but no predators), intermediate species (I: species with both prey and predator) and basal species (B: species with predator but no prey). In our studied food webs, these types of species corresponded to the fishes, macroinvertebrates and different types of detritus, respectively. The variations on the original extended food web are presented in Table 1. Throughout this study, we used the key of variations shown in this table. The cluster column identifies those species that were aggregated, while maintaining the other components as they are in the original food web. 
Table 1. Key of food web aggregation variations to the original extended food web

\begin{tabular}{l|c|c}
\hline $\begin{array}{c}\text { Aggregation variations of food } \\
\text { webs }\end{array}$ & Key & Clusters \\
\hline $\begin{array}{l}\text { Original } \\
\text { Fish }\end{array}$ & OFW & FFW \\
Macroinvertebrates & MFW & $\begin{array}{c}\text { *None } \\
\text { *Aggregation of Intermediate species: } \\
\text { Macroinvertebrate cluster in Functional } \\
\text { Feeding Groups }\end{array}$ \\
Detritus & DFW & $\begin{array}{c}\text { *Aggregation of Basal species: Detritus } \\
\text { taxa cluster }\end{array}$ \\
\hline
\end{tabular}

In FFW, fish species were aggregated into single taxa. In another aggregation, macroinvertebrate taxa were lumped according to their Functional Feeding Group: scrapers, shredders, filterers, collectors and predators (MFW), while different types of detritus (CPOM, suspended FPOM, deposited FPOM and benthonic detritus) were aggregated into single taxa (DFW). Proceeding in this way, 24 different food webs were created, comprising three variations on the original food web in each of the six studied streams. Each food web consisted of a different combination of lumped species in each stream.

\section{Structural properties of food webs}

We calculated a suite of 18 properties for each food web (Williams and Martinez, 2000; Bersier et al., 2002; Dunne et al., 2004; Romanuk et al., 2006) using software developed for previous food web studies (Williams and Martinez, 2000; Williams et al., 2002; Yoon, 2004). These food web properties were: Species richness $(S)$ (number of all species compartments in the web), Fish species richness $(F)$ (number of fish species in the web) and Macroinvertebrate species richness (Inv) (number of all invertebrate taxa in the web). Six properties give percentages related to the types of species found within the web: top species $(T)$ (percentage of species with prey but no predators or parasites), intermediate species (I) (percentage of species with both prey and predators), basal species (B) (percentage of species with predator but no prey), omnivory (Omn) (percentage of species with food chains of different lengths, where a food chain is a linked path from a non-basal to a basal species, i.e., the percentage of species that feed directly on more than one trophic level), percentage of herbivores plus detritivores (Herb), and the percentage of species involved in looping (Loop) by appearing in a food chain twice.

Two standard measures of trophic interaction richness in the food webs are reported: linkage density $(L / S)$, links per species, the number of all trophic links in the web (L) divided by $\mathrm{S}$, and Connectance $(C)$, where $\mathrm{C}=\mathrm{L} / \mathrm{S}^{2}$, the proportion of all possible trophic links $\left(\mathrm{S}^{2}\right)$ that are actually realized $(\mathrm{L})$, ranges from 0 (no taxa preys on any other taxa) to 1 (every taxa preys on every other species including itself).

As carried out by Dunne et al., (2004), we calculated the measure of trophic level known as the Short-weighted trophic level $(T L)$, this property gives the most accurate estimate of trophic level based on binary link information (Williams and Martinez 2004), and also its maximum value, the Short-weighted trophic level maximum (MaxTL). 
We report measures related to predator and prey species: standard deviation of mean generality $(G e n S D)$, the number of prey items a species has, the standard deviation of vulnerability (VulSD), and how many predators a species has. These two measures quantify the variability of the normalized predator and prey counts for a given species. Trophic similarity (Sim) is the number of predators and prey shared in common by a pair of species divided by the total number of predators and prey of that pair. The maximum index of similarity was calculated for each species in order to calculate the average maximum trophic similarity (MaxSim). A simple measure of prey:predator ratio $(P: P)$ ([percentage of basal + intermediate species]/[percentage of top + intermediate species]; Cohen, 1977) was used to describe the shape of the food web (high values, more triangular; low values, a "square" food web) (Thompson and Townsend, 2003). All of these are commonly calculated properties that have been reviewed in previous studies (Williams and Martinez, 2000; Dunne et al., 2004; Romanuk et al., 2006).

\section{Data analysis}

A two way nested ANOSIM was used to examine the properties of food webs (Clarke and Warwick, 2001), testing for similarities between streams, with aggregation variations nested within site. The same analysis was carried out to determine the effect of applying aggregation. In addition, a single factor analysis of similarities was performed in this case to test for significant similarities between pairs of food webs with different groupings. Two-dimensional MDS (Multidimensional Scaling) ordination was carried out for each aggregation variation within the original extended food web. All (24) food webs were clustered using hierarchical agglomerative clustering (Bray-Curtis similarities). In these analyses, we removed those properties related to food web size (S, F and Inv). Spearman R correlations were carried out using the statistical software SPSS 14.0 to examine the relationships between food web properties in each aggregation variation. Although the relationships between all the studied structural properties in the different food web aggregation variations were determined, only those of most interest are presented here.

\section{Results}

As expected, a decline of the resolution in trophic species led to a reduction in the number of elements within the food web (Fig. 1.a.). Macroinvertebrate food webs (MFW) exhibited the greatest decrease in $S$, since this food web aggregation variation grouped the highest percentage of species; specifically, between 45 and $60 \%$ of the total number of species in all streams. This decrease in the number of components of the food web affected the top (T), intermediate (I) and basal species (B) proportions differently, depending on the level at which the lumping of elements occurred. The proportion of intermediate species was reduced by the grouping of macroinvertebrate taxa, producing an increase in $T$ and $B$ species (Fig. 1.b., 1.c. and 1.d.). Most intermediate species were herbivores or detritivores, and thus this variation (MFW) produced a similar effect in Herb property (Fig. 1.e.)

The property with the lowest variation between aggregation variations of food webs was Omn (Fig. 1.f.), i.e. values of omnivory in different variations food webs were closer to the original than those of any other properties. The largest deviation from the original food web was found in the Chanza stream, where FFW and MFW underestimated and overestimated control values, respectively. On the one hand, the 
Chanza had the highest number of omnivorous fish, thus grouping the fish into a single taxa (in FFW) and decreasing the proportion of omnivorous species, while on the other, aggregation of the macroinvertebrate taxa into five functional groups caused a reduction of intermediate species and the establishment of simple trophic links between the top and basal species. This caused the proportion of species that feed over different trophic levels to increase relative to the original extended food web.
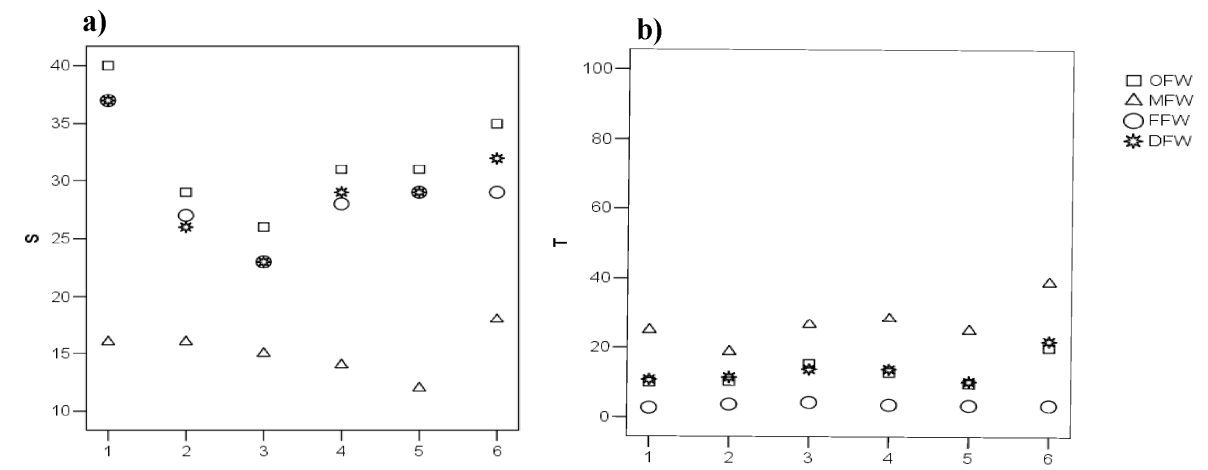

d)
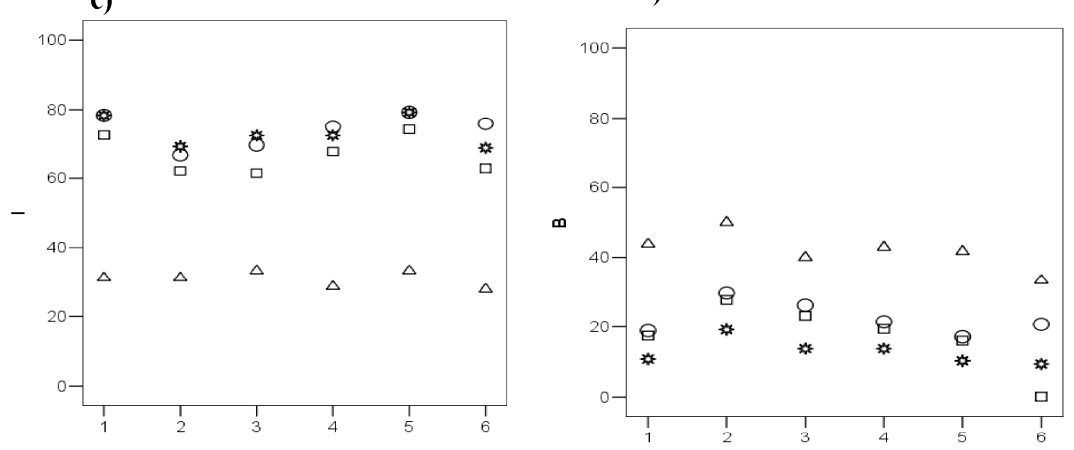

e)

f)
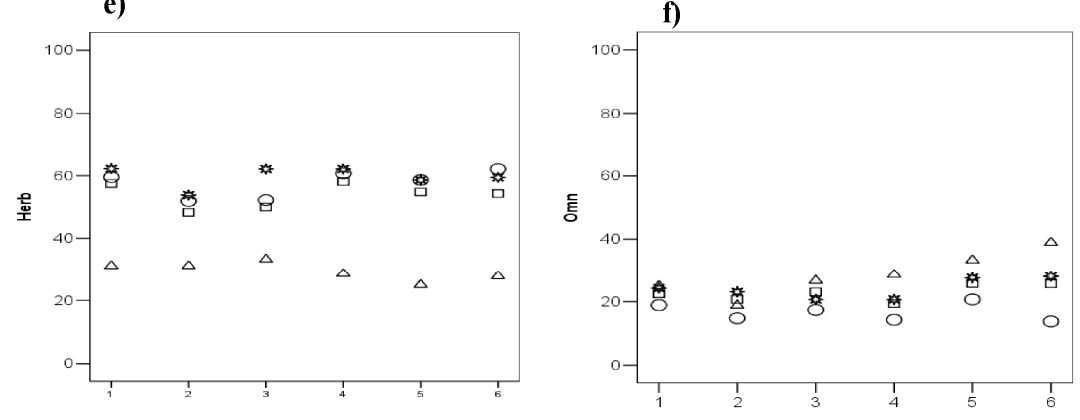

Figure 1. Richness and proportion of taxa (S, T, I, B, Omn and Herb) for each food web aggregation variation (OFW: , MFW: $\triangle, F F W: \circ$ and DFW: Hozgarganta, 2 = Guadiaro, $3=$ Guadiamar, $4=$ Rivera de Cala, $5=$ Odiel and $6=$ Rivera de

Chanza)

Regarding the properties of food webs related to link richness and linkage complexity, connectance (C) and linkage density (L/S) were affected in different way by species clustering (Fig. 2.a and 2.b). FFW underestimated these properties, since a reduction in the number of fish species produced a greater decrease in link richness than in species richness, leading to lower $\mathrm{L} / \mathrm{S}$ and $\mathrm{C}$ values. The opposite effect was observed when different forms of detritus were joined as single taxa (DFW), i.e. both properties 
were overestimated due to the decrease in species richness, while link richness remained constant.

TL tended to decrease with increased aggregation of food web components; MFW was therefore the variation which caused the most underestimation of this property, followed by FFW. DFW produced greater values than those obtained by the original extended food web (OFW) (Fig.2.c). When the number of intermediate or top species declined (MFW and FFW respectively), those elements of the food web with TL $>1$ were deleted, producing an estimated mean trophic level of the food web below that of the original. However, when basal elements of the food web were lumped, those species with lower TL $(\mathrm{TL}=1)$ were deleted, resulting in an overestimation of the mean trophic level for the whole food web.

a)

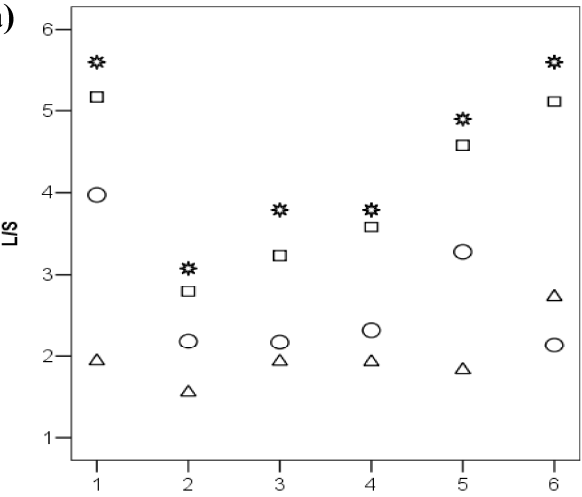

c)

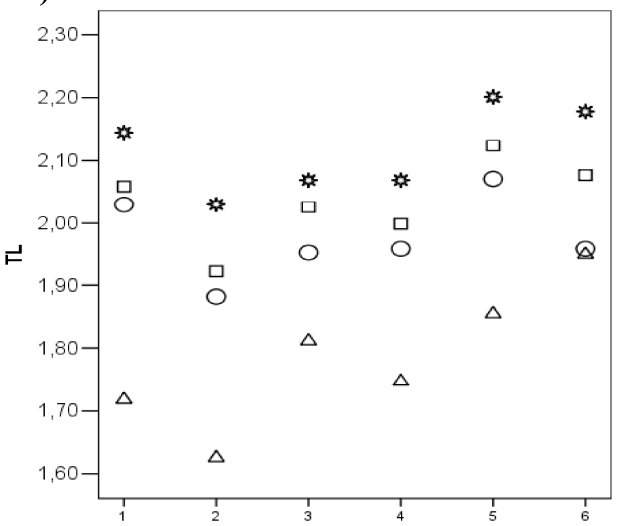

b)

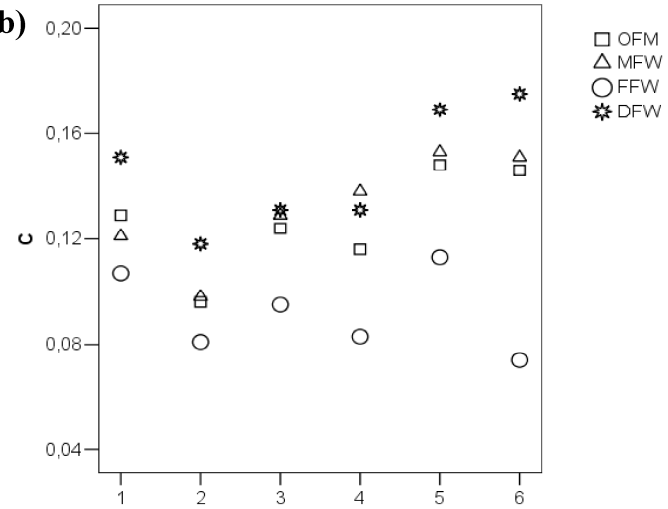

d)

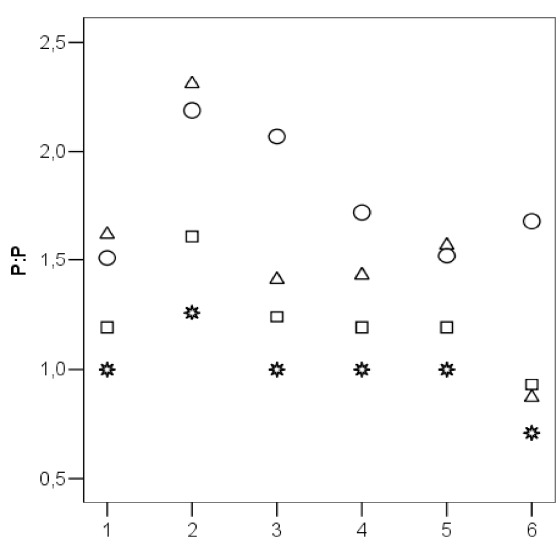

Figure 2. Properties of trophic interaction richness, trophic level and prey: predator ratio $(L / S$, $C, T L, P P)$ for each food web aggregation variation (OFW: , MFW: $, F F W: \circ$ and $D F W:$ : in each studied stream. $(1=$ Hozgarganta, $2=$ Guadiaro, $3=$ Guadiamar, $4=$ Rivera de Cala, $5=$ Odiel and $6=$ Rivera de Chanza)

Prey: predator ratio (P:P) was greatly affected by aggregation at different habit trophic levels (Fig.2.d.). When only basal species were aggregated (DFW), the result was a reduction in prey items, producing a P:P ratio lower than that of the original food web. Aggregation of the top and intermediate species (FFW and MFW, respectively) produced a reduction in the number of predators in the food web, increasing the P:P ratio relative to the original values of the control food web (OFW). 
The 24 constructed food webs were plotted together on an ordination graph according to the analyzed structural properties (Fig. 3). They are represented in clusters related to aggregation variations, but with no relation to stream effects: We found that the stream effect was insignificant (ANOSIM: Global Rho $=0.016, p=0.367$ ) while the effect of aggregation variations was found to be significant (ANOSIM: Global Rho = $0.625, \mathrm{p}=0.001)$. DFW showed the closest values to OFW. Thus, the results for the pairwise test in this analysis showed that no significant differences existed between the original extended food web (OFW) and the food web where different forms of detritus were aggregated into a single group (DFW) (Table 2).

Table 2. Results of a pairwise test in Anosim analysis between aggregation variations. OFW: Original Food Web, FFW: Fish Food Web, MFW: Macroinvertebrate Food Web and DFW: Detritus Food Webs

\begin{tabular}{c|c|c}
\hline & Global Rho & $\boldsymbol{p}$ \\
\hline OFW-MFB & 0.741 & 0.002 \\
OFW-FFW & 0.331 & 0.011 \\
OFW-DFW & 0.035 & 0.264 \\
MFW-FFW & 1.000 & 0.002 \\
MFW-DFW & 0.896 & 0.002 \\
FFW-DFW & 0.552 & 0.002 \\
\hline
\end{tabular}

In terms of empirical structural properties, percentages of similarity were high within and between different aggregation variations of food webs: values were found to be greater than $85 \%$ in all cases (Table 3). As had been expected, OFW and DFW comprised the pair of aggregation variations with the greatest similarity values. The main properties which explained dissimilarity between different food web variations were those related to the trophic habit of species: T, I, B, Loop, Herb and Omn.

The effects of aggregation on the estimation of empirical structural properties caused a variation in the relationship between food webs, within a variation type (Table 4). Therefore, the relationships between structural properties differed according to a given aggregation variation of the food web. One exception to this was the relationship between connectance and omnivory, which was significant and positive in all the food webs derived from the different aggregation variations.

Table 3. Similarities in structural properties within and between different food web aggregation variations. Results are expressed as percentage similarity. OFW: Original food web, FFW: Fish food web, MFW: Macroinvertebrate food web and DFW: Detritus food web.

\begin{tabular}{c|c|c|c|c}
\hline & OFW & FFW & MFW & DFW \\
\hline OFW & 92.25 & & & \\
FFW & 90.91 & 94.59 & & \\
MFW & 87.81 & 86.02 & 96.58 & \\
DFW & 92.67 & 90.05 & 87.50 & 93.33 \\
\hline
\end{tabular}



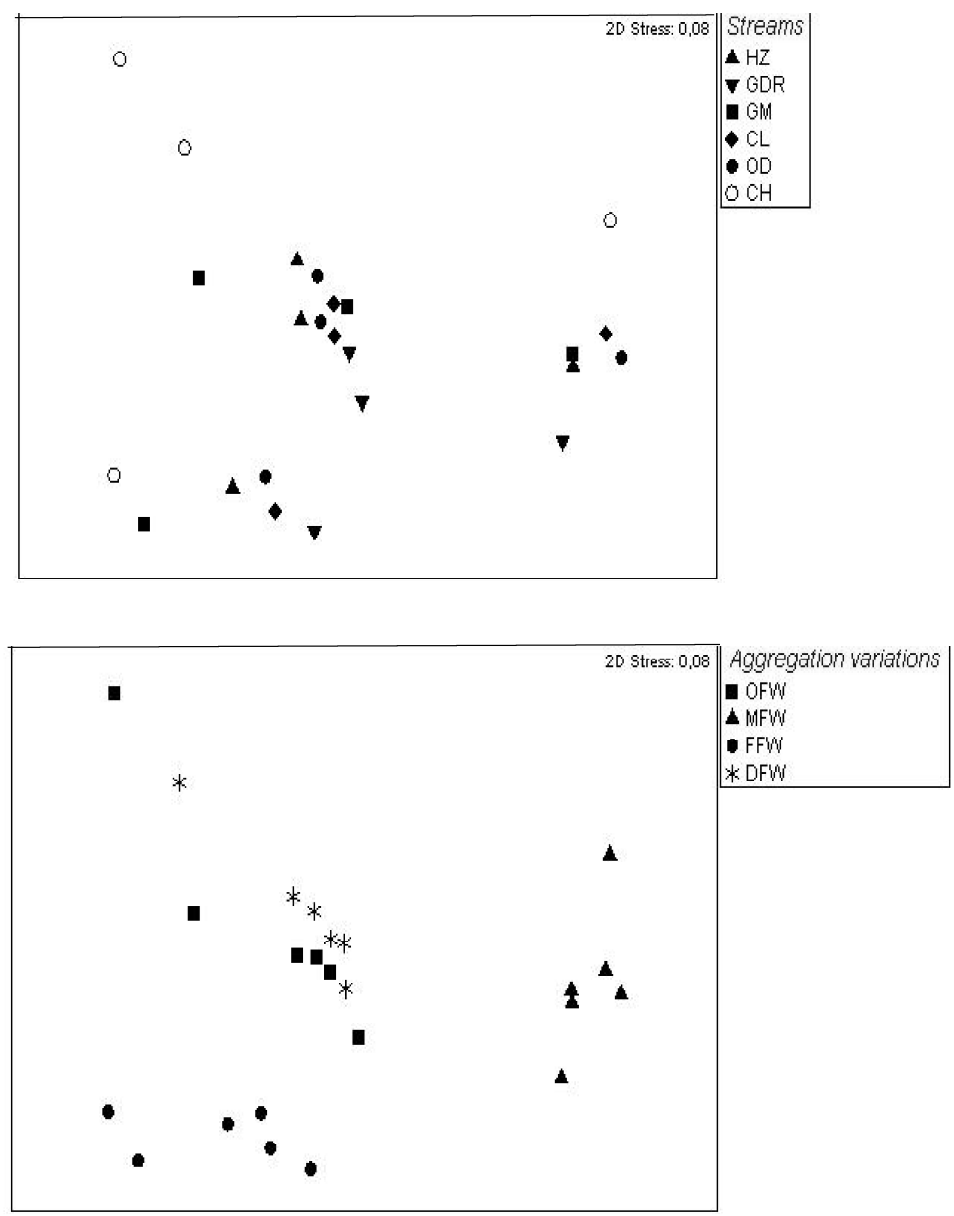

Figure 3. Two-dimensional MDS ordination of 24 constructed food webs by their structural properties. Hierarchical agglomerative clustering was used (Bray-Curtis similarities) (up: labels according to streams; down: labels according to aggregation variations)

Table 4. Spearman rank correlation coefficient between selected structural properties in each food web aggregation variation. (Numbers shown in italics represent significant correlations). OFW: Original food web, FFW: Fish food web, MFW: Macroinvertebrate food web and DFW: Detritus food web. ${ }^{*}<0,05 y *{ }^{*} p<0,01$

\begin{tabular}{c|c|c|c|c}
\hline & OFW & FFW & MFW & DFW \\
\hline Inv-L/S & $0.886^{*}$ & 0.657 & 0.414 & $0.841^{*}$ \\
Inv-C & 0.657 & 0.429 & -0.621 & 0.667 \\
$C-O m n$ & $0.886^{*}$ & $0.943^{* *}$ & $0.943^{* *}$ & $0.824^{*}$ \\
$C-L / S$ & 0.714 & 0.771 & 0.200 & $0.824^{*}$ \\
$C-T L$ & $0.999 * *$ & 0.667 & $0.886^{*}$ & $0.941^{* *}$ \\
\hline
\end{tabular}

\section{Discussion}

In general, it is neither possible to identify all the species, nor measure all the flows present within a food web. For this reason, it is broadly accepted that food webs can normally be aggregated into a manageable size for interpretation and analysis, and many studies have focused on the effects of taxonomic aggregation on food web properties (Yodzis and Winemiller, 1999; Jordan, 2003; Ludczkovich et al., 2003; Krause et al., 2003). 
Omnivory and weak interactions between detritivorous and detritus play stabilizing roles in the food web of Mediterranean streams. In this work, we review food web structure in such streams and demonstrate that the lumping of their components and the level at which this occurs has a great impact upon the properties of the empirical structure of the food web. Utilization of the same resolution for analysis in different streams allowed these properties to be comparable within these ecosystems. Thus, the intuitive belief that better information is gained from looking more closely (increasing the level of resolution) would only be valid if standard levels of resolution can be maintained across different studies (Thompson and Townsend, 2000).

As expected, the original (control) food web maintained the highest $S$ values. A decrease in resolution produced a concomitant reduction in the number of food web elements and it may be that the change in connectance reflects smaller web size rather than a change in resolution per se. (Thompson and Townsend, 2000). In our study, the food web aggregation variation that joined macroinvertebrates in five functional feeding groups (MFW) had values of connectance cosest to those of the extended original food web (OFW). In spite of this, these types of food webs differed mostly in terms of the number of total elements. We suggest that here, food web size did not dramatically affect connectance when most of grouped species were detritivorous with weak interactions with the detritus.

Our study achieved an appropriate resolution at the macroinvertebrate and fish level; however, we were not able to include meiofauna or bacteria, and the periphyton algae were left as a single group. Some studies have demonstrated the importance of meiofauna in food webs (Schmid-Araya and Schmid, 2000; Schmid-Araya et al., 2002). In these studies, the inclusion of meiofauna in the food web analysis produced increased complexity and pattern modification. However, although it is important to increase the accuracy of analysis, it is not always feasible to describe all the trophic components in exhaustive detail. Taxa clustering effects prey: predator ratios such that failure to resolve lower trophic levels adequately is likely to produce the false impression of food webs being very "square" in structure (featuring low prey: predator ratios) and this can obscure any dietary specialisation occurring among primary consumers (Thompson and Townsend, 2000).

As Yodzis and Winemiller (1999) pointed out, the main issue is to clarify the constraints of the community and be rigorous in food web depiction, which is a reliable method for producing comparable food webs. In this study, we considered clustering the periphyton algae into a single group in all the food web aggregation variations. However, we observed that lumping another basal species instead (the different forms of detritus) had the same effect as expected by the grouping of periphyton algae, i.e. lower prey: predator ratio values.

The type of grouping carried out and the level (i.e. with species of superior, intermediate or basal level) at which it is done, proved to be important and therefore must be taken into account. We suggest that, in order to study food web structure in Mediterranean streams, it is advisable to utilize a resolution which goes beyond considering superior and intermediate taxa as one or more groups. Authors such as Haven et al. (1996) point out that conducting studies that consider all trophic levels is necessary for correct analysis of food webs. However, most studies performed in streams have been designed with a special emphasis upon macroinvertebrates only (Closs and Lake, 1994; Tavares-Cromar and Williams, 1996; Corigliano and Malpassi 1998; Thompson and Townsend, 1999). Hence, we propose that fish should be included 
in the food web at a resolution level of species instead of simply being considered as a single group. The use of this aggregation is common practice in this type of ecosystems that produce values of structural properties that differ from the original values.

In general, the properties of those food web aggregation variations which lumped different forms of detritus into a single group were those most similar to original values. This outcome suggests that considering different forms of detritus as a single compartment could produce a reliable estimate for assessing food web topology. However, Allesina et al. (2002) suggest that considering detritus as one compartment would result in the neglect of important information regarding ecosystem functioning. We need to focus further on this issue to obtain more conclusive results; however, according to our findings in Mediterranean streams, the consideration of detritus as a single group did not significantly affect the general food web structure.

An interesting observation arising from this study was that aggregation did not affect one of the clearest and most relevant relationships in Mediterranean stream food websthat which exists between omnivory and connectance. Omnivory, defined broadly as feeding on more than one trophic level, occupies a prominent position in discussions concerning the structure and dynamics of food webs. Classical conceptual syntheses suggest that omnivory should be a strongly stabilizing factor in food webs (McCann et al., 1998), and the stabilizing role of omnivory has been the topic of more recent works (Melián and Bascompte, 2002; Bascompte and Melián, 2005). The properties of connectance and omnivory were both positive and significantly related in all the food web aggregation variations, suggesting that the stabilizing role of omnivory is maintained regardless of which part of the ecosystem is under investigation.

Our study contributes to understanding the consequences of lumping species into groups of convenience in the assessment of food webs. The grouping of some food web components affects structural properties and the relationships that exist between them. The only connection unaffected by this practice is that which exists between connectance and omnivory. We recognize that more comprehensive data is required to draw fully conclusive results; however, we suggest that aggregating fish or macroinvertebrates into large groups could produce the greatest modification to the overall structure of the food webs in these rivers. Thus, when drawing conclusions about general trophic structure, investigators should consider how the components of the ecosystem have been grouped.

Acknowledgments. This study was financially supported by the Spanish Ministry of Education and Science (BOS2002-01265). We thank J. Dunne and R.J. Williams, from Pacific Ecoinformatics and Computational Ecology Lab (Berkeley, EE.UU.) for providing access to the FoodWebKB software (www.foodwebs.org).

\section{REFERENCES}

[1] Abarca-Arenas, L.G., Ulanowicz, R.E. (2002): The effects of taxonomic aggregation on network analysis. - Ecol. Model. 149: 285-296.

[2] Allesina, S., Bondavalli, C., Scharler, U.M. (2005): The consequences of the aggregation of detritus pools in ecological networks. - Ecol. Model.: 221-232. DOI 10.1016/j.ecolmodel.2005.04.2002.

[3] Bascompte, J., Melián, C.J. (2005): Simple trophic modules for complex food webs. Ecology 86: 2868-2873. 
[4] Bersier, L.F., Banasek-Richter, C., Cattin, M.F. (2002): Quantitative descriptors of food-webs matrices. - Ecology 83: 2394-2407. DOI 10.2307/3071801.

[5] Clarke, K.R., Warwick, R.M. (2001): Change in marine communities: an approach to statistical analysis and interpretation. - Plymouth Marine Laboratory, Plymouth, UK.

[6] Closs, G. (1991): Multiple definitions of food web statistics: an unnecessary problem for food web research. - Australian Journal of Ecology 16: 413-415.

[7] Closs, G.P., Lake, P.S. (1994): Spatial and Temporal Variation in the Structure of an Intermittent-Stream Food Web. - Ecol. Monogr. 64: 2-21.

[8] Cohen, J.E. (1977): Ratio of prey to predators in community food webs. - Nature 270: 165-167.

[9] Cohen, J.E., Beaver, R.A., Cousins, S.H., DeAngelis, D.L., Goldwasser, L., Heong, K.L., Holt, R.D., Kohn, A.J., Lawton, J.H., Martinez, N.D., O’Malley, R., Page, L.M., Patten, B.C., Pimm, S.L., Polis, G., Rejmanek, M., Schoener, T.W., Schoenly, K., Sprules, W.G., Teal, J.M., Ulanowicz, R.E., Warren, P.H., Wilbur, H.M., Yodzis, P. (1993): Improving Food Webs. - Ecology 74: 252-258.

[10] Corigliano, M.C., Malpassi, R. (1998): Food web structure in riffles and marginal pools of a mountain stream. - Verh. Interna. Verein. Limnol. 26: 996-1001.

[11] Cummins, K.W., Klug, M.J. (1979): Feeding ecology of stream invertebrates. - Ann. Rev. Ecol. Syst. 10: 147-172.

[12] Doadrio, I. (2001): Atlas y Libro Rojo de los Peces Continentales en España. Ministerio de Medio Ambiente, Madrid, España.

[13] Dunne, J., Williams, R.J., Martinez, N.D. (2004): Network structure and robustness of marine food webs. - Mar. Ecol. Prog. Ser. 273: 291-302. DOI 10.3354/meps273291.

[14] Fath, B.D., Schaler, U.M., Ulanowicz, R.E., Hannon, B. (2007): Ecological network analysis: network construction. - Ecol. Model. 208: 49-55. DOI 10.1016/j.ecolmodel.2007.04.029.

[15] Gaedke, U. (1995): A comparison of whole-community and ecosystem approaches (biomass size distributions, food web analysis, network analysis, simulation models) to study the structure, function and regulation of pelagic food webs. - J. Plankton Res. 17: 1273-1305.

[16] Gasith, A., Resh, V.H. (1999): Streams in mediterranean climate regions: Abiotic Influences and Biotic Responses to Predictable Seasonal Events. - Ann. Rev. Ecol. Syst. 30: 51-81.

[17] Goldwasser, L., Roughgarden, J. (1997): Sampling effects and the estimation of food web properties. Ecology 78: 41-54.

[18] Hall, S.J., Raffaelli, D.G. (1991): Food-web patterns: lessons from a species-rich web. - J. Anim. Ecol. 60: 823-842.

[19] Havens, K.E., Bull, L.A., Warren, G.L., Crisman, T.L., Philips, E.J., Smithm J.P. (1996): Food web structure in a subtropical lake ecosystem. - Oikos 75: 20-29.

[20] Hildrew, A.G. (2009): Sustained research on stream communities: a model system and the comparative approach. - Ad. Ecol. Res. 41: 175-312.

[21] Johnson, G.A., Niquil, N., Asmus, H., Bacher, C., Asmus, R., Baird D. (2009): The effects of aggregation on the performance of the inverse method and indicators of network analysis. $\quad-$ Ecol. Model. 220: 3448-3464. DOI 10.1016/j.ecolmodel.2009.08.003.

[22] Jordan, F. (2003): Comparability: the key to the applicability of food web research. AEER 1: 1-18.

[23] Kottelat, M., Freyhof, J. (2007): Handbook of European Freshwater fishes. Publications Kottelat. Switzerland.

[24] Krause, A.E., Frank, K.A., Mason, D.M., Ulanowicz, R.E. (2003): Compartments revealed in food-web structure. - Nature 426: 282-285.

[25] Lawton, J., Warren, P. (1988): Static and dynamic explanation of patterns in food webs. - Trends Ecol.Evol. 3: 242-245. 
[26] Liu, X-Q., Wang, H.Z., Liang, X.N. (2006): Food web of macroinvertebrate community in a Yangtze shallow lake: trophic basis and pathways. - Hydrobiologia 571: 283-295.

[27] Luczkovich, J.J., Borgatti, S.P., Johnson, J.C., Everett, M.G. (2003): Defining and measuring trophic role similarity in food web using regular equivalence. $-\mathrm{J}$. Theor. Biol. 220: 303-321.

[28] Martinez, N.D. (1991): Artefacts or attributes? Effects of resolution on the Little Rock Lake food web. - Ecol. Monogr. 61: 367-392.

[29] Martinez, N.D. (1993): Effects of resolution on food webs structure. - Oikos 87: 77-85.

[30] Martinez, N.D. (1994): Scale-dependent constraints on food web structure. - American Naturalist 144(6): 935-953.

[31] Martinez, N.D., Hawkins, B.A., Dawah, H.A., Feifarek, B.P. (1999): Effects of sampling effort on characterization of food web structure. Ecology 80: 1004-1055.

[32] Martinez, N.D., Lawton, J.H. (1995): Scale and food-web structure-from local to global. Oikos 73: 148-154.

[33] McCann, K., Hasting, A., Huxel, G.R. (1998): Weak trophic interactions and the balance of nature. - Nature 395: 794-798.

[34] Melián, C.J., Bascompte J. (2002): Complex networks: two ways to be robust? - Ecol. Lett. 5: 405-708.

[35] Merrit, R.W., Cummins, K.W. (1996): An introduction to the aquatic insects of North America. - Kendall/Hunt Publishing Company, Dubuque, Iowa, USA.

[36] Motta, R.L., Uieda, V.S. (2005): Food web structure in a tropical stream ecosystem. Austral Ecol. 30: 58-73. DOI 10.111/j.1442-9993.2005.01424.x.

[37] Paine, R.T. (1980): Food webs: linkage, interaction strength and community infrastructure. - J. Anim. Ecol. 49: 667-685.

[38] Pimm, S.L. (2002): Food webs. - Chapman and Hall, London.

[39] Pinkas, L., Oliphant, M.S., Inverson, I.L.K. (1971): Food habitats of albacore, bluefin tuna and bonito in California waters. - Fishery Bulletin 152: 1-139.

[40] Polis, G.A., Hurd, S.D. (1995): Extraordinarily high spider densities on islands: flow and energy from the marine to territorial food webs and the absence of perdition. PNAS 92: 4382-4386.

[41] Romanuk, T.N., Jackson, L.J., Post, J.R., McCauley, E., Martinez, N.D. (2006): The structure of food webs along river networks. - Ecography 29: 3-10. DOI 10.1111/j.2005.0906-7590.04181.x.

[42] Schmid-Araya, J.M., Hildrew, A.G., Robertson, A., Schmid, P.E., Winterbottom, J. (2002): The importance of meiofauna in food webs: evidence from an acid stream. Ecology 83: 1271-1285.

[43] Schmid-Araya, J.M., Schmid, P.E. (2000): Trophic relationships: integrating meiofauna into a realistic benthic food web. - Freshwater Biol. 44: 149-63.

[44] Sugihara, G., Bersierk, L.F., Schoenly, K. (1997): Effects of taxonomic and trophic aggregation on food web properties. - Oecologia 112: 272-284.

[45] Tachet, H., Richoux, P., Bournaud, M., Usseglio-Polatera, P. (2003): Invertebratébrés d'eau douce. Systematique, biologie, écologie. - CNRS Editions. Paris.

[46] Tavares-Cromar, A.F., Williams, D.D. (1996): The importance of temporal resolution in food web analysis: evidence from a detritus-based stream. - Ecol. Monogr. 66: 91113.

[47] Thompson, R.M., Townsend, C.R. (1999): The effect of seasonal variation on the community structure and food web attributes of two streams: implications for food web science. - Oikos 87: 75-88.

[48] (2000): Is resolution the solution?: the effect of taxonomic resolution on the calculated properties of three stream food webs. - Freshwater Biol. 44: 413-422.

[49] (2003): Impacts on stream food webs of native and exotic forest: an intercontinental comparison. - Ecology 84: 145-161. 
[50] Williams, R.J., Berlow, E.L., Dunne, J.A., Barabási, A.L., Martinez, N.D. (2002): Two degrees of separation in complex food webs. - PNAS 99: 12913-12916. DOI 10.1073/pnas.192448799.

[51] Williams, R.J., Martinez, N.D. (2000): Simple rules yield complex food webs. - Nature 404: 180-183. DOI 10.1038/35004572.

[52] Williams, R.J., Martinez, N.D. (2004): Limits to trophic levels and omnivory in complex food webs: theory and data. - Am. Nat. 163: 458-467. DOI 10.1086/381964.

[53] Winemiller, K.O. (1996): Factors driving temporal and spatial variation in aquatic floodplain food webs. - In: Polis, G.A., Winemiller, K.O. (Eds.) Food webs integration of patterns and dynamic, Chapman \& Hall, N.J, pp. 298-312.

[54] Yodzis, P. (1984): How rare is omnivory? - Ecology 65: 321-323.

[55] Yodzis, P., Winemiller, K.O. (1999): In search of operational trophospecies in a tripical aquatic food web. - Oikos 87: 327-340.

[56] Yoon, I., Williams, R.J., Levine, E., Yoon, S., Dunne, J.A., Martinez, N.D. (2004): Webs on the Web (WoW): 3D visualization of ecological networks on the WWW for collaborative research and education. - Proceedings of the IS\&T/SPIE Symposium on Electronic Imaging, Visualization and Data Analysis 5295:124-132. 